\title{
Role of hydroxycarbamide in prevention of complications in patients with sickle cell disease
}

This article was published in the following Dove Press journal:

Therapeutics and Clinical Risk Management

18 September 2009

Number of times this article has been viewed

\section{NM Wiles \\ J Howard}

Department of Haematology, St Thomas' Hospital, Westminster Bridge Road, London, SEI 7EH, UK
Correspondence: J Howard Department of Haematology, St Thomas' Hospital, Westminster Bridge Road, London, SEI 7EH, UK

Email jo.howard@gstt.nhs.uk

\begin{abstract}
Sickle cell disease (SCD) is a genetically inherited condition caused by a point mutation in the beta globin gene. This results in the production of the abnormal hemoglobin, sickle hemoglobin (HbS). Hydroxycarbamide, is an antimetabolite/cytotoxic which works by inhibiting ribonucleotide reductase, blocking the synthesis of DNA and arresting cells in the $\mathrm{S}$ phase. In sickle cell anemia, it promotes fetal hemoglobin (HbF) synthesis, improves red cell hydration, decreases neutrophil and platelet count, modifies red cell endothelial cell interactions and acts as a nitric oxide donor. Trials have shown the clinical benefit of hydroxycarbamide in a subpopulation of adult patients with SCD, with a $44 \%$ reduction in the median annual rate of painful crises, a decrease in the incidence of acute chest syndrome and an estimated $40 \%$ reduction in overall mortality over a 9-year observational period. Its use in pediatrics has also been well established; trials have shown it is well tolerated and does not impair growth or development. In addition it decreases the number and duration of hospital attendences. A number of emerging uses of hydroxycarbamide currently are being investigated, such as stroke prevention.
\end{abstract}

Keywords: sickle cell anemia, hydroxycarbamide, hydroxyurea, maximum tolerated dose, vaso-occlusive crisis

\section{Introduction}

Sickle cell disease (SCD) is a genetically inherited condition caused by a point mutation causing the substitution of valine for glutamic acid at position 6 in the beta globin gene. This results in the production of the abnormal hemoglobin, sickle hemoglobin ( $\mathrm{HbS})$. The clinical phenotype can be seen in patients with homozygous sickle cell disease (HbSS), but also in patients who are compound heterozygotes of $\mathrm{HbS}$ and another abnormal hemoglobin such as hemoglobin C, D, E or O-Arab or beta thalassemia. Sickle cell disease is now the most common genetic disorder in the UK, affecting over 1 in 2000 live births and up to 1 in 300 births in some urban areas, and there is a worldwide annual birthrate of over 200,000 of which more than $90 \%$ are in Africa. ${ }^{1}$ $\mathrm{HbS}$ polymerizes at low oxygen levels, making the red cell initially more rigid, and eventually irreversibly sickled. These red cells are less deformable and this results in vaso-occlusion within the end organ capillaries, leading to pain and organ dysfunction. In addition, ongoing hemolysis has an important role in disease pathophysiology by causing nitric oxide (NO) deficiency and vascular instability. ${ }^{2}$ Red blood cell dehydration and red cell adhesion to the endothelium, with subsequent endothelium activation also contribute to the pathophysiology of this condition. ${ }^{3}$ Despite being a single gene disorder there is considerable heterogeneity in the clinical severity seen, and this is thought to be in part due to the role of other genetic factors, such as the co-inheritance 
of alpha thalassemia, and the presence of several single nucleotide polymorphisms (SNPs). ${ }^{4}$

Despite being one of the first inherited diseases characterized, treatment for SCD in the UK has lagged behind that in many other conditions. Hydroxycarbamide (also known as hydroxyurea), has a FDA license for the prevention of the complications of SCD in adults and is associated with improvements in morbidity in the adult and pediatric sickle populations.

\section{Hydroxycarbamide - mechanism of action}

Hydroxycarbamide has been used for decades in many hematological disorders, in particular the myeloproliferative disorders as a myelosuppressive agent. The first investigations into hydroxycarbamide as an agent that could potentially alter the production of fetal hemoglobin $(\mathrm{HbF})$ was in anemic baboons, 5,6 and it was first shown to raise levels of $\mathrm{HbF}$ in patients with SCD in $1985 .^{7}$

Hydroxycarbamide belongs to a class of compounds called hydroxamic acids, which can bind metals. It inhibits ribonucleotide reductase by binding to two iron molecules on the reductase and inactivating a critical tyrosyl radical. ${ }^{8}$ This accounts for its cytotoxic effect which is beneficial in many ways; it targets rapidly dividing cells, which in red cells tend to be those with a high level of $\mathrm{HbS}$, and favors the production of red cells with a high $\mathrm{HbF}$, as these tend to arise from red cells that divide less rapidly.

Another potential mechanism of action is the production of NO caused by the metabolism of hydroxycarbamide. Hydroxycarbamide activates guanylate cyclase, an enzyme containing heme, via a NO-dependent mechanism, which results in the production of $\mathrm{HbF}$, as shown in vitro. The mechanism by which hydroxycarbamide generates $\mathrm{NO}$ is thought to be related to the NO/guanosine 3,5-cyclic monophosphate (cGMP) pathway in erythroid progenitor cells. ${ }^{9}$ The production of NO may also compensate for the loss of endogenous NO due to intravascular hemolysis.

Hydroxycarbamide has additional effects including a reduction in the numbers of white cells and platelets, potentially reducing their roles in vascular injury ${ }^{10}$ and also improves red cell hydration and decreases red cell adhesiveness to the endothelium. ${ }^{11,12}$

\section{Role of hydroxycarbamide in prevention of acute painful crises and acute chest crises}

Systematic reviews have looked at all randomized or quasi-randomized controlled trials comparing the use of oral hydroxycarbamide with placebo, standard therapy or other interventions for the treatment of patients with SCD. ${ }^{13,14}$ Only 2 out of 7 studies ${ }^{15,16}$ were suitable for inclusion in these reviews and they are described in detail below. One further study is ongoing. ${ }^{17}$ These reviews concluded that hydroxycarbamide appeared effective in severely affected adults with $\mathrm{HbSS}$ over a 2-year period; however, further studies are required to elucidate its role in other patient groups. In addition all individuals should be counseled prior to commencing therapy relating to the known and potential risks.

\section{Adult trials}

\section{Multicenter Study of Hydroxyurea (MSH) ${ }^{15}$}

This was the first phase III double-blind, randomized controlled trial to look at the efficacy of hydroxycarbamide in reducing the frequency of painful sickle crises. Two hundred and ninetynine adults with HbSS and a history of 3 or more crises a year were included and were randomly assigned to receive hydroxycarbamide $(n=152)$ or placebo $(n=147)$. Hydroxycarbamide was initiated at $15 \mathrm{mg} / \mathrm{kg} /$ day and increased every 12 weeks by $5 \mathrm{mg} / \mathrm{kg} /$ day until the maximum tolerated dose (MTD) was reached. If marrow depression occurred, it was stopped until blood counts recovered and restarted at a dose $2.5 \mathrm{mg} / \mathrm{kg}$ lower than the previous dose, starting a new 12-week cycle. The patients were seen every 2 weeks and blood samples taken. A painful crisis was defined as a visit to a medical facility lasting more than 4 hours and requiring parenteral or oral narcotics. In addition patients filled out daily pain diaries, reviewed at each clinic visit.

There was a median rate of 2.5 crises per year in the hydroxycarbamide group, compared to 4.5 in the placebo group, which represented a $44 \%$ difference $(P<0.001)$. When crises severe enough to warrant hospitalization were compared, the median annual rates were 1.0 in the hydroxycarbamide group and 2.4 in the placebo group $(P<0.001)$. The incidence of chest syndrome also differed significantly with 25 patients developing acute chest syndrome (ACS) in the hydroxycarbamide group vs 51 in the placebo group $(P<0.001)$. Both the frequency of blood transfusions (48 vs 73, $P=0.001$ ) and number of red cell units transfused (336 vs 586, $P=0.004$ ) were decreased in the group receiving hydroxycarbamide. There was no significant difference in the incidence of death, stroke and hepatic sequestration between the two groups.

The trial was stopped early, after 21 months of follow-up because of the beneficial results observed. $\mathrm{Hb}$, mean cell volume $(\mathrm{MCV}), \mathrm{HbF}$ and proportion of $\mathrm{HbF}$ cells were higher in the hydroxycarbamide group than the placebo 
group at the time of study closure, and white blood cell count (WBC), platelets and reticulocyte counts were lower. They found the beneficial effects of hydroxycarbamide do not become manifest for several months, differences between the two groups in terms of $\mathrm{MCV}$ and $\mathrm{HbF}$ percent becoming apparent from 8 weeks. No deaths owing to treatment were described in the trial and no patients developed neoplastic disorders. Treatment was permanently stopped in 14 patients in the hydroxycarbamide group for medical reasons and 6 in the placebo group. Treatment ceased temporarily in almost all of the patients treated with hydroxycarbamide because of marrow depression; blood counts recovered within approximately 2 weeks. Hydroxycarbamide was associated with a raised hemoglobin in 11 patients, and despite it exceeding $12 \mathrm{~g} / \mathrm{dL}$, there were no adverse events.

This was an important study which demonstrated the clinical benefit of hydroxycarbamide in patients with severe homozygous SCD, which significantly reduced the median annual rate of painful crises and the incidence of ACS. It left further questions to be answered about optimal dose, further application, any benefit to prevent long-term organ damage, and long-term safety and tolerability data.

The MSH subsequently published 9-year follow-up observational data ${ }^{18}$ which estimated that there was a $40 \%$ reduction in overall mortality in the patients who had taken hydroxycarbamide. Complete data for 233 out of the original 299 patients were obtained for the full 9 years, and during the follow-up study they were able to continue, stop or start hydroxycarbamide and were seen yearly from 1996 to 2001. Data were included from the beginning of the original MSH trial, which showed that 96 patients $(31 \%)$ never received hydroxycarbamide, $48(16 \%)$ received hydroxycarbamide for less than 1 year and $156(52 \%)$ received hydroxycarbamide for 1 or more years. From the initial patient cohort, 25\% (75) died during the trial or follow-up, 28 of the deaths being due to pulmonary complications. When the deaths were analyzed in terms of original randomized patient subgroups, there were no differences between the hydroxycarbamide and placebo arms, but this did not take into account the patients' treatment after the original randomized phase was completed. There was a difference in cumulative mortality between the 2 subgroups, although this was not statistically significant $(P=0.35)$. Patients with reticulocyte counts less than $250,000 / \mathrm{mm}^{3}$ and hemoglobin levels $<9 \mathrm{~g} / \mathrm{dL}$ had increased mortality $(P=0.002)$. Cumulative mortality at 9 years was $28 \%$ when $\mathrm{HbF}$ levels were $0.5 \mathrm{~g} / \mathrm{dL}$ or higher $(P=0.03)$. Individuals who had ACS during the trial had $32 \%$ mortality compared with $18 \%$ of individuals without ACS $(P=0.02)$.
Patients with 3 or more painful episodes per year during the trial had $27 \%$ mortality compared with $17 \%$ of patients with less frequent episodes $(P=0.04)$. There were 3 cases of cancer, 1 case of in situ cervical cancer who had received 63 months of hydroxycarbamide, 1 of breast carcinoma after 47 months of hydroxycarbamide and 1 patient died of endometrial carcinoma after 9 years of hydroxycarbamide.

Analyzing mortality in 3-month intervals according to hydroxycarbamide usage in the interval, death rates were reduced $40 \%$ during the 3 -month intervals when patients were taking hydroxycarbamide $(P=0.04)$. Overall, the follow-up trial showed that adult patients taking hydroxycarbamide for frequent painful sickle episodes appear to have reduced mortality after 9 years of follow-up, and estimated this to be in the order of $40 \%$ overall reduction. Survival was related to $\mathrm{HbF}$ levels and frequency of vaso-occlusive events. These results must be interpreted with care as this is an observational study in which patients could choose whether or not they took the hydroxycarbamide.

\section{Pediatric trials Belgian study ${ }^{16}$}

This randomized single blind placebo crossover trial of hydroxycarbamide, looked at 25 children and young adults with a median age of 9 years (range 2 to 22 years). They were randomized between placebo and hydroxycarbamide at a dose of $20 \mathrm{mg} / \mathrm{kg} /$ day for 2 weeks and the dose was increased to $25 \mathrm{mg} / \mathrm{kg} /$ day if there was no increase in HbF. After 6 months they were switched to the other treatment. Three patients on the placebo and 16 on the hydroxycarbamide had no hospitalizations during the 6 months of treatment, and there were no clinically relevant toxicities, implying that hydroxycarbamide decreased the incidence of painful crises in children as well as in adults.

\section{Belgian Registry data ${ }^{19,20}$}

Data from the Belgian Registry were initially published in $2001^{20}$ and updated in 2004. ${ }^{19}$ One hundred and twenty-seven patients with SCD were enrolled into the registry between 1993 and 2002 and started on hydroxycarbamide; 99 for 2 or more vaso-occlusive crisis (VOC), 21 for an ACS, 7 for stroke, 1 for transient ischemic attack (TIA), and 18 for abnormal trans-cranial dopplers (TCDs) only. One hundred and nineteen patients had $\mathrm{HbSS}, 4 \mathrm{HbS} \beta^{0}$ thalassemia, $3 \mathrm{HbSC}$ and $1 \mathrm{HbSD}$. The median age at entry was 6 years ( 8 months to 19 years) and mean follow up was 47 months (1 to 8 years).

Hydroxycarbamide dosing was started at $20 \mathrm{mg} / \mathrm{kg} /$ day and escalated in increments of $5 \mathrm{mg} / \mathrm{kg}$ if felt appropriate by 
the treating physician. The mean number of hospitalizations and duration of hospital admissions dropped significantly during the 8 years of hydroxycarbamide treatment $(P<0.05)$. Ninety-two out of 109 (85\%) patients treated with hydroxycarbamide for conventional clinical criteria were free of major events requiring hospitalization at 1 year. At 7 and 8 years after initiation of treatment 6/24 (25\%) and 5/14 (36\%) patients respectively, remained so.

Thirty-two patients with $\mathrm{HbSS}$ were monitored for 6 years to assess the long term effects of hydroxycarbamide therapy. The median age at entry was 6 years (range 8 months to 19 years). Hospitalizations, acute painful crisis and ACS were more frequently observed during the fourth to sixth year of treatment than during the first 3 years. During the 6 years of hydroxycarbamide treatment 8/32 (25\%) patients remained free from any SCD-related event requiring hospitalization. No strokes or TIA occurred in the 31 patients without a previous history of neurological events. There was 1 recurrent stroke in an 8-year-old girl, 6 years after the initial event. The hydroxycarbamide dose was reduced over time with no effect on the hematological indices.

In the registry, 14 patients were less than 2 years old at the time of enrolment and of these 10 had a minimum followup of 2 years hydroxycarbamide therapy. Their clinical events and hospitalizations were similar to those in older age groups over the same time period, the hospitalization durations being longer in the younger group.

\section{HUG-KIDS study ${ }^{21}$}

This was a phase I-II pediatric hydroxycarbamide trial used to determine if hydroxycarbamide would have a detrimental effect on the growth of school-aged children with HbSS. ${ }^{19}$ This prospective observational trial enrolled 68 children and adolescents who had an age range of 5 to 16 years and included 28 female and 40 male patients. Patients were eligible if they had severe SCD with 3 or more painful events in 1 year or 3 or more episodes of ACS in the 2 years before trial entry and hydroxycarbamide was escalated to MTD. In addition they needed a minimum of 6 documented height and weight measurements recorded for at least 2 years preceding entry. They had serial height, weight and Tanner stage measurements during the study. Comparison data were obtained from the data from the Co-operative Study of Sickle Cell Disease (CSSCD), and 3 groups were compared: pretreatment HUG-KIDS, on-treatment HUG-KIDS and the CSSCD group. In girls, there were no significant differences in height or weight among the pre-treatment, on-treatment and CSSCD groups. Compared with the CSSCD groups,
HUG-KIDS boys were heavier from 9 years of age (although not statistically significant) and pre-treatment HUG-KIDS boys were taller from 7 years of age $(P>0.05)$. The Tanner stage transitions took place at appropriate ages. This study showed that treatment with hydroxycarbamide had no adverse effect on height or weight gain or pubertal development in school-aged children with SCD.

\section{Hydroxyurea Safety and Organ Toxicity trial (HUSOFT)}

The original HUSOFT trial ${ }^{22}$ investigated the short term feasibility of hydroxyurea administration, toxicities, hematologic effects and effect on spleen function in infants with SCD. This was a prospective, multicenter, open-label, single arm, pilot study. In the 2-year initial study, 28 infants with $\mathrm{HbSS}$ or $\mathrm{HbS} \beta^{0}$ thalassemia, all unselected for disease severity between 6 and 28 months (median 15 months), were prospectively treated with hydroxycarbamide. This was given orally once a day at the fixed dose of $20 \mathrm{mg} / \mathrm{kg}$ as a liquid formulation.

Twenty-one infants completed 2 years of hydroxycarbamide treatment. Hydroxycarbamide was well tolerated, produced mild toxicities, predominantly transient neutropenia, which was associated with a presumed viral infection in $70 \%$. None had an associated invasive viral infection. Persistent or recurrent neutropenia required a decrease in dose in 3 patients. Anemia and thrombocytopenia were rare and no significant hepatic or renal toxicity was observed. Two patients had accidental overdoses of hydroxycarbamide, which resulted in a mild transient neutropenia in both. No adverse effects on growth were observed compared with untreated controls. There was maintenance of relatively stable elevated hemoglobin and HbF levels, showing a clear response to hydroxycarbamide therapy. The study also suggested a possible beneficial effect on preservation of splenic function, but the numbers were too low for statistical significance.

The HUSOFT extension study followed on from this pilot study. ${ }^{23}$ This reported on the long-term efficacy and toxicity of hydroxycarbamide in infants. All 21 infants completing the original 2-year pilot study were offered continued liquid hydroxycarbamide therapy, and their dose was escalated by $5 \mathrm{mg} / \mathrm{kg}$ every 6 months to a maximum dose of $30 \mathrm{mg} / \mathrm{kg} /$ day. Of the 21 patients enrolled, 1 was removed because of non-compliance and 1 patient did not tolerate the dose increase, because of neutropenia. This patient required a permanent dose reduction to $27.5 \mathrm{mg} / \mathrm{kg} /$ day. Seventeen completed an additional 4 years, and 11 were treated for a total of 6 years. Removal from the study before 6 years was 
due to non-compliance (in 4), parents' request (4) recurrent ACS (1) and death from pneumococcal sepsis (1).

Increased and sustained values of $\mathrm{Hb}, \mathrm{MCV}, \mathrm{HbF}$ and $\mathrm{F}$ cells were observed during the extension trial. All patients who tolerated the dose escalation responded to hydroxycarbamide by raising the percentage of $\mathrm{HbF}$. Levels of WBC, platelet count and reticulocyte levels were lower than those expected in untreated children and were lower at year 6 than year 3, possibly because of dose escalation. The treated patients had significantly fewer ACS events than untreated SCD patients; however there was no difference in the incidence of pain. This was attributed to the method of data collection as in this trial pain was recorded monthly whereas in some other trials, eg, the CSSCD study, pain frequency was recorded annually retrospectively.

Hydroxycarbamide was generally well tolerated, with $8 \%$ cases of neutropenia compared to $10 \%$ in the pilot study above. Growth was not impaired among these children treated with hydroxycarbamide compared to standard growth curves. There was improved growth in some children, especially boys, a finding which has previously been demonstrated in boys ${ }^{21}$ and school-age children. ${ }^{24} \mathrm{~A}$ trend towards a delay in functional asplenia was observed and recovery of splenic function in was seen in 2 cases. There was no decrease in the rate of silent infarcts after 4 years of hydroxycarbamide therapy $(21 \%)$, compared to the prevalence reported in untreated SCD children.

In conclusion, the extension study supported the findings of the initial pilot study described above that hydroxycarbamide is effective in young children, with little acute toxicity. In addition it showed the use of oral liquid formulation of hydroxycarbamide at a dose of $30 \mathrm{mg} / \mathrm{kg} /$ day is feasible, results in sustained hematological efficacy with relatively limited adverse events, decreases the ACS rate, and may improve growth.

\section{Monitoring and dosing of hydroxycarbamide}

Hydroxycarbamide has only recently been licensed for use in SCD in the UK, and the majority of UK patients are currently being prescribed the unlicensed formulation. In view of this, and the lack of long-term follow up data for hydroxycarbamide, it is vital that full informed consent is taken from patients who are commenced on hydroxycarbamide therapy and the use of a patient information sheet is advised. Hydroxycarbamide therapy is usually commenced at a starting dose of $15 \mathrm{mg} / \mathrm{kg}$ (rounded to the nearest $500 \mathrm{mg}$ ), as in the MSH study ${ }^{15}$ and the full blood count should be checked 2 weeks after initiation and after each dose increase. Once stable the full blood count should be checked every 6 to 8 weeks. If the patient is still symptomatic, then dose escalation should take place every 4 weeks until the blood count falls. At this point the hydroxycarbamide should be stopped until the full blood count has recovered and restarted at $2.5 \mathrm{mg} / \mathrm{kg}$ or $500 \mathrm{mg}$ lower. This is the MTD. Liver function tests and urea and electrolytes should be checked every 8 weeks. HbF levels should also be checked regularly as this gives a good indication of response as does an increase in MCV. There are no studies looking at optimal timing of dose escalation and blood monitoring but UK expert opinion would support the above strategy. ${ }^{25}$

Hydroxycarbamide is renally excreted so dosage should be adjusted in patients with evidence of renal impairment, and a starting dose of $7.5 \mathrm{mg} / \mathrm{kg}$ should be given in patients with a glomerular filtration rate of less than $60 \mathrm{~mL} /$ minute. $^{26}$

\section{Maximum tolerated dose or minimum effective dose?}

The majority of trials using hydroxycarbamide, including $\mathrm{MSH}$, have commenced treatment at $15 \mathrm{mg} / \mathrm{kg}$ or $20 \mathrm{mg} / \mathrm{kg}$ and escalated treatment to the MTD or a maximum dose of $30 \mathrm{mg} / \mathrm{kg}$. It is not clear on current evidence whether it is necessary to dose escalate in this way, or whether patients should be treated with the minimum effective dose. Although the patients enrolled in the MSH study were intended to dose escalate to the MTD, many did not, only $33 \%$ of patients receiving the MTD by 6 months, and $53 \%$ at the time of study closure, suggesting that hydroxycarbamide is effective at doses lower than the MTD. Hydroxycarbamide therapy at the MTD has been shown to be well tolerated and has sustained hematologic efficacy over several years of therapy. ${ }^{27}$ In this trial hydroxycarbamide was initiated in 122 patients with severe SCD $(106 \mathrm{HbSS}, 7 \mathrm{HbSC}$, and $\mathrm{HbS} / \beta$ thalassemia and $2 \mathrm{HbS} / \mathrm{O}_{\text {Arab }}$ ) at a median age of 11.1 years (range 0.5 to 19.7 years). Hydroxycarbamide was escalated to the MTD, with an average dose of $25.4 \pm 5.4 \mathrm{mg} / \mathrm{kg} /$ day. The average duration of treatment was $45 \pm 24$ months. Of the 122 patients, 21 received doses higher than $30 \mathrm{mg} / \mathrm{kg} /$ day (median $31.1 \mathrm{mg}$, range 30.1 to $36.1 \mathrm{mg} / \mathrm{kg} /$ day). It was discontinued in 15 children with poor compliance.

There were significant increases for all of the 122 patients in hemoglobin level, MCV, and $\mathrm{HbF}$ level. When analyzed according to genotype, the increase in hemoglobin concentration was significant in all but the 8 patients with $\mathrm{HbSC}$ or $\mathrm{HS} / \beta^{+}$. Hydroxycarbamide led to a decrease in the rate of hemolysis, as shown by significant decreases in reticulocyte count and bilirubin levels. In addition, there were significant 
decreases in WBC and platelet counts. Mild transient neutropenia occurred in $5 \%$ of patients, but there was no hepatic or renal toxicity. There were no adverse effects on growth while on therapy, and many children had improved growth.

$\mathrm{HbF}$ induction was sustained for up to 8 years reaching levels of up to $20 \%$ which is the level suggested to provide clinical benefit. ${ }^{28}$ This was achieved without adverse effects on growth or increased numbers of DNA mutations as measured by the quantitative VDJ assay to look for acquired somatic mutations. No child on hydroxycarbamide in this study acquired myelodysplasia, leukemia or any other malignancy. These data showed that escalating the dose of hydroxycarbamide to the MTD in children could achieve the maximum and sustained beneficial hematologic effects on percentage $\mathrm{HbF}$ and $\mathrm{WBC}$ count but they did not show that a decrease in clinical severity paralleled the dose increases.

In adults, it has been shown that it is not always necessary to reach the MTD to produce good clinical effects. ${ }^{29}$ There is no current evidence to suggest that either MTD or minimum effective dosing regimes are safer or more efficacious and there are no long-term safety data beyond 8 years in children and 9 years in adults.

\section{Adverse effects of hydroxycarbamide}

The most common short-term side effect of hydroxycarbamide is myelosuppression, which requires careful monitoring with regular blood tests.

There is no established evidence of malignancy caused by the use of hydroxycarbamide in SCD, but there have been a small number of cases of leukemia and lymphoma reported. ${ }^{15,30}$ This needs to be discussed with the patient and balanced against the improvement in symptoms and mortality.

Animal studies have shown hydroxycarbamide to be embryotoxic/teratogenic, ${ }^{31}$ causing a number of birth defects. There have been 58 pregnancies reported in 57 women exposed to hydroxycarbamide during pregnancy which include one case of a fetal death and reduced growth and several minor malformations. ${ }^{32}$ The advice given currently to both male and female patients is not to conceive while on hydroxycarbamide and for 3 months after cessation. Clinicians should ensure that their patients are aware of the recommendation to use contraception whilst on hydroxycarbamide. If a woman becomes pregnant while on hydroxycarbamide she should stop it immediately and should not recommence until breast feeding has stopped.

There are limited data on male fertility after ceasing hydroxycarbamide, and there is some evidence that fertility does not return to normal in all patients, even several months after cessation. Males' sperm counts have been well described to be affected during therapy with hydroxycarbamide, predominantly in animal studies but also in a number of case studies, ${ }^{32}$ one study showing up to $40 \%$ of men had decreased sperm counts while on hydroxycarbamide. ${ }^{33}$ There are several case reports showing a long-term effect of hydroxycarbamide on sperm counts, including a case of a sickle patient who became azoospermic after 7 months' treatment with hydroxycarbamide who still had significantly reduced sperm count and sperm motility at 1 year after cessation of treatment. ${ }^{34} \mathrm{~A}$ retrospective review of 4 patients on hydroxycarbamide, 3 with sickle cell and 1 with myeloproliferative disease (MPD), showed variable effects on spermatogenesis. Unfortunately no pre-hydroxycarbamide data were available. The MPD patient was azoospermic while on hydroxycarbamide, and regained a normal sperm count, but with many abnormal forms and motility 3 months after cessation. Once hydroxycarbamide was restarted he again became azoospermic. A second patient had a normal count throughout treatment but reduced motility, although sperm count fell once treatment was ceased. The 3rd and 4th patients did not have data both on and off hydroxycarbamide. ${ }^{35}$

A further study has looked at the effects of hydroxycarbamide on sperm parameters, in 4 patients with sequential data, on and off hydroxycarbamide therapy. ${ }^{33}$ Of these, one became azoospermic, which persisted 4 years after cessation. Two others developed reduced sperm counts on hydroxycarbamide, which did not recover 3 to 5 years after stopping treatment. One patient's sperm count was not affected during treatment, but there were concerns about the patient's compliance.

The data from the above observational studies, although in small numbers, raise the question for the need to provide analysis and possible sperm banking for males starting hydroxycarbamide. The authors would recommend that sperm analyses and banking are offered to all men about to commence hydroxycarbamide therapy, and that semen analysis is performed annually during therapy and when therapy is stopped. Ideally this should be done as part of a clinical trial.

Other side effects include hyperpigmentation of nails, nausea and vomiting, skin rash, alopecia and diarrhea. There was no evidence of an increased incidence of leg ulcers in the MSH study, despite the association of hydroxycarbamide therapy and leg ulcers in myeloproliferative disease. ${ }^{36}$

\section{UK guidelines - current indications for hydroxycarbamide}

In the UK, there are recently published standards for the clinical care of adults and children with SCD which outline the indications for the use of hydroxycarbamide. ${ }^{37,38}$ 
These are peer-reviewed documents based on literature review and expert opinion. In adults ${ }^{37}$ hydroxycarbamide therapy is recommended for patients with moderate to severe SCD who have had 3 painful crises per year over the past 2 years requiring hospital admission, or have recurrent crises in the community which are severe enough to interfere with their activities of daily living, or who have had 2 or more acute chest syndromes, or 1 severe acute chest syndrome requiring ventilation.

Further possible indications, based on observational studies or anecdotal reports, include the following: Patients who have had a previous stroke, but are no longer willing or able to continue a transfusion program; patients with excessive hemolysis causing anemia; patients with repeated gallstone formation; or patients with anemia owing to renal disease, especially if they are not willing or able to have blood transfusion, pulmonary hypertension and priapism.

The pediatric guidelines ${ }^{38}$ recommend that hydroxycarbamide should be considered in patients who have recurrent episodes of acute pain (more than 3 admissions in the previous 12 months, or are very symptomatic in the community) or who have had 2 or more episodes of acute sickle chest syndrome, or 1 acute chest syndrome requiring ventilation. They also state that the decision to start hydroxycarbamide should be made by the specialist center, although the local hospital will have a role in monitoring blood counts and side effects. The specialist center should have a written protocol which is shared with the local hospital. This should include information about dose regimen, frequency of blood test monitoring, management of myelosuppression and contraindications for use of hydroxycarbamide. In addition the patient and/or their parents should be given a patient information sheet and the use of hydroxycarbamide should be discussed with them on at least 2 separate occasions. Current knowledge about side effects, including cytopenias and the possible risk of leukemia or other malignancies, should be discussed. This discussion should be documented in the patient's notes.

The guidelines also state that there are still some areas which need clarification. These are the optimal dose; impact on long-term organ function; and risk of malignancy. For these reasons, they recommend that its use should be monitored with collection of data about long-term outcomes.

\section{Emerging indications for hydroxycarbamide} Use of hydroxycarbamide to prevent stroke Transcranial doppler (TCD) ultrasound is now recommended as a routine screening test for children with SCD from
2 to 16 years of age, to identify patients at highest risk for primary stroke. ${ }^{39,40}$ There are emerging data that hydroxycarbamide may have a beneficial effect in primary or secondary prevention of stroke in children but its role relative to that of blood transfusion has not been defined by prospective trials. Until more data are available, blood transfusion is the modality of choice in treatment and prevention of stroke in SCD.

\section{Primary prevention}

The Belgian Registry data included a subgroup of 18 patients who were treated with hydroxycarbamide because they were at risk of stroke on the basis of an abnormal TCD. They did not meet the conventional criteria for commencing hydroxycarbamide. Eleven of these 18 patients were prospectively followed by TCD, and 2 had velocities that returned to normal/conditional on hydroxycarbamide. In addition 8 patients at risk of secondary stroke were treated with hydroxycarbamide and followed for a median of 6 years. At trial entry only 5 of the 8 were still receiving chronic transfusion. Recurrent stroke occurred in 1 patient during the 6 years of follow-up. Thirty-four patients from the entire Belgian Registry (of 127 patients) were considered to be at risk of primary stroke on the basis of abnormal TCD, and only $1 / 34$ presented with a cerebrovascular accident during an evaluation of 96 patient years. Evidence of silent infarction or neuropsychological change was not examined in this population. ${ }^{19}$

A prospective phase II trial has also looked at the efficacy of hydroxycarbamide in primary prevention. ${ }^{41}$ TCD velocities were examined in 59 children who were initiating hydroxycarbamide therapy because of clinical severity. Thirty-seven out of the 59 had increased flow velocities ( $>140 \mathrm{~cm} / \mathrm{second}$ ) at enrolment. The TCD velocities were then measured at MTD and at 1 year later. At the MTD, significant decreases were observed in the right and left middle cerebral artery velocities $(P<0.001)$. The magnitude of TCD velocity decline was significantly correlated with the maximal baseline TCD value. At hydroxycarbamide MTD, 14/15 children with conditional baseline TCD values improved, while the TCD reduction of $5 / 6$ patients with abnormal TCD velocities whose families refused transfusions decreased to $<200 \mathrm{~cm} /$ second. These TCD changes were sustained at follow-up. A further prospective single-center trial has been reported which followed up 14 infants for 80 weeks or more. This group had a median age of 35 months (range 21 to 53 months) and was treated with the MTD of hydroxycarbamide. Three patients had a conditional TCD at trial entry and these all reverted to the normal range by the end of the trial. No new MRI or MRA lesions were seen during the trial. ${ }^{42}$ 


\section{Secondary prevention}

In 16 patients with $\mathrm{SCD}$ and previous stroke, transfusion therapy was prospectively discontinued and hydroxycarbamide was initiated. At the time of reporting the patients had been off transfusion for a median of 22 months (3 to 52 range). Their average hemoglobin was $9.4 \pm 1.3 \mathrm{~d} / \mathrm{dL}$ and 14 patients underwent phlebotomy. Three patients (19\%) had neurological events considered recurrent stroke, each 3 to 4 months after discontinuing transfusions, but before maximal hydroxycarbamide effects. These data suggested that some patients may be able to discontinue chronic transfusions and use hydroxycarbamide therapy to prevent stroke recurrence. ${ }^{43}$

A further study ${ }^{44}$ looked at hydroxycarbamide as an alternative to transfusion in 5 children with SCD who had had a stroke, 3 after the first episode and 2 after the second CVA. Four had had an infarctive stroke, and 1 a TIA. None of the 5 patients had recurrence during 2 to 112 months of observation.

\section{Phase III Stroke With Transfusions Changing to Hydroxyurea (SWiTCH) trial}

A phase III trial ${ }^{46}$ is currently underway including approximately 130 children (5.0 to 18.9 years of age with 65 subjects per treatment arm) with SCD who have had symptomatic cerebral infarctions and have been treated with red cell transfusions for at least 18 months. After completing baseline screening studies, half the participants will be switched to a therapeutic program of hydroxyurea and phlebotomy. Half of the participants will remain on transfusion and chelation. The composite primary endpoint is to compare two modalities of treatment for the prevention of secondary stroke and management of iron overload. Hopefully this will provide some clear guidance as to the definitive role of hydroxycarbamide in the prevention of secondary stroke.

Conclusions from current evidence are that blood transfusion should be the treatment of choice for primary or secondary stroke prevention, but that hydroxycarbamide should be considered in patients who refuse or are unable to receive blood transfusion therapy. Further information will be obtained from the SWiTCH trial.

\section{Effects on splenic function}

There is emerging evidence, although not at all conclusive, that hydroxycarbamide may positively affect splenic function in children. The HUSOFT study suggested a possible delay in the progression toward functional asplenia corroborated in the HUSOFT extension study. ${ }^{23}$ After 4 years of treatment with hydroxycarbamide there was a lower proportion of asplenic patients on hydroxycarbamide treatment (43\% vs the expected 94\%), suggesting that hydroxycarbamide may be able to prevent the loss of splenic function. It does however raise the possibility of a prolonged risk of acute splenic sequestration in these patients which will need further investigation.

Additionally, a more recent retrospective review looked at splenic function at baseline and on treatment with hydroxycarbamide in 43 children. ${ }^{46}$ After a median of 2.6 years (range 0.2 to 8.6 years) of hydroxycarbamide at the MTD, 6 patients (14\%) completely recovered splenic function and $2(5 \%)$ had preserved splenic function. These 8 children had a greater hemoglobin concentration on hydroxycarbamide therapy than

Table I Current UK indications for use of hydroxycarbamide in adult and pediatric sickle cell disease

\begin{tabular}{|c|c|c|}
\hline Indications in adults ${ }^{33}$ & & Indications in children ${ }^{34}$ \\
\hline $\begin{array}{l}\text { Absolute indications } \\
\text { (grade } \mathrm{A} \text { evidence) }\end{array}$ & $\begin{array}{l}\text { Possible indications } \\
\text { (based on observational studies } \\
\text { or anecdotal reports) }\end{array}$ & $\begin{array}{l}\text { Absolute indications } \\
\text { (grade } \mathrm{A} \text { evidence) }\end{array}$ \\
\hline $\begin{array}{l}3 \text { painful crises per year over the past } \\
2 \text { years requiring hospital admission }\end{array}$ & $\begin{array}{l}\text { Previous stroke, but are no longer } \\
\text { willing or able to continue a } \\
\text { transfusion program }\end{array}$ & $\begin{array}{l}\text { Recurrent episodes of acute pain } \\
(>3 \text { admissions in the previous } \\
12 \text { months, or are very symptomatic } \\
\text { in the community) }\end{array}$ \\
\hline $\begin{array}{l}\text { Recurrent crises in the community } \\
\text { which are severe enough to interfere } \\
\text { with their activities of daily living }\end{array}$ & $\begin{array}{l}\text { Excessive hemolysis causing } \\
\text { anemia or repeated gallstone } \\
\text { formation } \\
\text { Anemia due to renal disease } \\
\text { Pulmonary hypertension } \\
\text { Priapism } \\
\text { Leg ulcers }\end{array}$ & 2 acute chest syndromes \\
\hline
\end{tabular}


those without splenic function $(9.1 \mathrm{vs} 8.6 \mathrm{~g} / \mathrm{dL}, P=0.01)$. Although retrospective, the data suggest that hydroxycarbamide at MTD possibly preserves spleen and can even result in recovery of splenic function. In addition they suggest higher final hemoglobin concentration during therapy is a significant laboratory predictor of improved splenic function.

\section{Use in renal impairment}

A prospective single center trial has been reported which followed up 14 infants for 80 weeks or more. This group had a median age of 35 months (range 21 to 53 months) and was treated with the MTD of hydroxycarbamide. DTPA glomerular filtration rate (GFR) was measured at trial entry and exit. Five children had a raised GFR of over $150 \mathrm{~mL} /$ minute at trial entry, implying hyperfiltration and early renal damage. At trial entry the GFR had not risen as expected in the group of patients with a normal GFR at trial entry and the GFR in two patients with a raised GFR at trial entry had returned to normal. ${ }^{42}$ A retrospective analysis of hydroxyurea in combination with enalapril in children with SCD and sickle nephropathy ${ }^{47}$ has looked at the laboratory effects of the two drugs. Enalapril reduced the urinary protein excretion and normalized serum albumin. There was a suggestion that the addition of hydroxycarbamide further normalized the urine/protein creatinine ratio. This would merit further investigation.

\section{Future areas for research Role of hydroxycarbamide in different genotypes}

The majority of trials listed above have been limited to patients with $\mathrm{HbSS}$, or included small numbers of patients with other genotypes, including $\mathrm{HbSC}, \mathrm{HbS}$ thalassemia, and HbSD. ${ }^{15,20,23}$ A decrease in frequency and severity of painful crises has been shown in studies of non-HbSS patients and this trial confirms subanalysis of other trials that patients with $\mathrm{HbSC}$ may tolerate lower doses of hydroxycarbamide before reaching the MTD. ${ }^{27,48}$ These have only involved small patient numbers and would merit further investigation.

\section{Other indications}

A single-center study has reported on an improvement in chronic hypoxia in 3 pediatric patients when treated with hydroxycarbamide. This would merit further investigation. ${ }^{49}$

\section{Pharmacotherapy combination}

There are many other agents currently being investigated, both individually and in combination with hydroxycarbamide.
They work in a variety of ways, some inducing $\mathrm{HbF}$, others by varying other mechanisms, such as inhibition of normal membrane ion exchange channels, inhibition of endothelial or cell surface adhesion molecules, and as nitric oxide modulators..$^{50}$

For example, in a recent report of the National Institutes of Health (NIH) experience, ${ }^{51} 13$ adult patients were given a combination of hydroxycarbamide and erythropoietin. These patients were either hydroxycarbamide intolerant due to reticulocytopenia, or had renal insufficiency. Erythropoetin plays an important role in dose escalation of hydroxycarbamide, while preventing erythroid toxicity, especially in the setting of renal impairment. An ongoing $\mathrm{NIH}$ phase I clinical trial is investigating the combination of these agents in adult patients with SCD and renal dysfunction and/or evidence of pulmonary hypertension (http:// www.clinicaltrials.gov\#NCT00270478). This will further clarify the role of erythropoietin and hydroxycarbamide combination therapy.

\section{Summary}

The efficacy of hydroxycarbamide in defined populations with SCD, both adult and pediatric, has been established since its first use in 1985. With its use has come a decrease in morbidity supplemented by increasing standards of care.

Unfortunately it is not a drug without side effects or risk and requires detailed pre-treatment counseling and careful monitoring of blood counts, which can limit compliance to therapy. Ongoing investigation into new agents may provide some further treatments; however at present hydroxycarbamide is the only effective treatment for patients with severe to moderate SCD. Its efficacy at reducing the frequency of vaso-occlusive crisis and acute chest crisis is well established. Its precise role and effects in certain populations such as stroke prevention and organ preservation is still being established, and some questions remain.

\section{Disclosures}

The authors disclose no conflicts of interest.

\section{References}

1. Serjeant GR. Sickle cell disease. Lancet. 1997;350:725-730.

2. Pawloski JR, Hess DT, Stamler JS. Impaired vasodilation by red blood cells in sickle cell disease. Proc Natl Acad Sci U SA. 2005;102: 2531-4648.

3. Hofrichter J, Ross PD, Eaton WA. Kinetics and mechanism of deoxyhaemoglobin $\mathrm{S}$ gelation: a new approach to understanding sickle cell disease. Proc Natl Acad Sci U S A. 1974;71:4864-4868.

4. Steinberg M. Genetic etiologies for phenotypic diversity in sickle cell anaemia. Scientific World Journal. 2009;9:46-67. 
5. Letvin NL, Linch DC, Beardsley GP, McIntyre KW, Nathan DG. Augmentation of fetal-hemoglobin production in anemic monkeys by hydroxyurea. N Engl J Med. 1984;310:869-873.

6. Platt OS, Orkin SH, Dover G, Beardsley GP, Miller B, Nathan DG. Hydroxyurea enhances fetal hemoglobin production in sickle cell anaemia. J Clin Invest. 1984;74:652-656.

7. Veith R, Galanello R, Papayannopoulou T, Stamatoyannopoulos G. Stimulation of F-cell production in patients with sickle cell anaemia treated with cytarabine or hydroxyurea. N Engl J Med. 1985;313: 1571-1575.

8. Yarbro JW. Mechanism of action of hydroxyurea. Semin Oncol. 1992; 19 Suppl 9:1-10.

9. Cokic VP, Smith RD, Beleslin-Cokic BB, et al. Hydroxyurea nitrosylates and activates soluble guanylyl cyclase in human erythroid cells. Blood. 2008;111:1117-1123.

10. Orah S, Platt MD. Hydroxyurea for the treatment of Sickle cell anaemia. N Eng J Med. 2008;358:1362-1369.

11. Orringer EP, Blythe DS, Johnson AE, Phillips G Jr, Dover GJ, Parker JC. Effects of hydroxyurea on hemoglobin F and water content in the red blood cells of dogs and of patients with sickle cell anaemia. Blood. 1991;78:212-216.

12. Hillery CA, Du MC, Wang WC, Scott JP. Hydroxyurea therapy decreases the in vitro adhesion of sickle erythrocytes to thrombospondin and laminin. Br J Haem. 2000;109:322-327.

13. Jones AP, Davies SC, Olujohungbe A. Hydroxyurea for sickle cell disease. Cochrane Database Syst Rev. 2009;3. Art. No.CD002202. DOI: 10.1002/14651858.CD002202.

14. Lanzkron S, Strouse JJ, Wilson R, et al. Systematic review: Hydroxyurea for the treatment of adults with sickle cell disease. Ann Int Med. 2008;148:939-955.

15. Charache S, Terrin ML, Moore RD, et al. Effect of hydroxyurea on the frequency of painful crises in sickle cell anaemia. Investigators of the Multicentre Study of Hydroxyurea in Sickle Cell Anaemia. $N$ Eng $J$ Med. 1995;332:1317-1322.

16. Ferster A, Vermylen C, Cornu G, Buyse M, Corazza F, Devalck C, et al. Hydroxyurea for the treatment of severe sickle cell anemia: a pediatric clinical trial. Blood. 1996;88:1960-1964.

17. Adams RJ, Barredo J, Bonds DR, Brown C, Casella J, Daner L, et al. TCD in infants: A report from the BABY HUG trial [abstract]. Blood. 2005;106:Abstract 952.

18. Steinburg MH, Barton F, Castro O, et al. Effect of hydroxyurea on mortality and morbidity in adult sickle cell anaemia: risks and benefits up to 9 years of treatment. JAMA. 2003;289: 1645-1651.

19. Gulbis B, Haberman D, Dufour D, et al. Hydroxyurea for sickle cell disease in children and for prevention of cerebrovascular events. The Belgian experience. Blood. 2005;105:2685-2690.

20. Ferster A, Tahriri P, Vermylen C, et al. Five years of experience with hydroxyurea in children and young adults with sickle cell disease. Blood. 2001;97:3628-3632.

21. Wang WC, Helms RW, Lynn HS, et al. Effect of hydroxyurea on growth in children with sickle cell anaemia: results of the HUG-KIDS Study. J Pediatr. 2002;140:225-229.

22. Wang WC, Wynn LW, Rogers ZR, et al. A two-year pilot trial of hydroxyurea in very young children with sickle cell anaemia. $J$ Paediatr. 2001;139:790-796.

23. Hankins JS, Ware RE, Rogers ZR, et al. Long-term hydroxyurea therapy for infants with sickle cell anaemia: the HUSOFT extension study. Blood. 2005;106:2269-2275.

24. Rodgers ZR. Hydroxyurea therapy for diverse paediatric populations with sickle cell disease. Semin Hematol. 1997;34:42-47.

25. Davies SC, Gilmore A. The role of hydroxyurea in management of sickle cell disease. Blood Rev. 2003;17:99-109.

26. Jan JH, Ataga K, Kaul S, et al. The influence of renal function on hydroxyurea pharmokinetics in adults with sickle cell disease. J Clin Pharmacol. 2005;45:434-445.
27. Zimmerman SA, Schultz WH, Davies JS, et al. Sustained long-term hematologic efficacy of hydroxyurea at maximum tolerated dose in children with sickle cell disease. Blood. 2004;103:2039-2045.

28. Noguchi CT, Rodgers GP, Serjent GR, SchechterAN. Levels of fetal hemoglobin necessary for treatment of sickle cell disease. $N$ Engl $J$ Med. 1988;318:96-99.

29. Lima CSP, Arruda VR, Costa FF, Saad STO. Minimal doses of hydroxyurea for sickle cell disease. Brazilian J Medical Biological Research.

30. de Montalambert M, Davies SC. Is hydroxyurea leukaemogenic in children with sickle cell disease? Blood Correspondance. 2001; 98:2878.

31. Brawley OW, Cornelius LJ, Edwards LR, Northington Gamble V, Green BL, Inturrisi C. National Institutes of Health Consensus Development Conference Statement: Hydroxyurea Treatment for Sickle Cell disease. Ann Int Med. 2008;148:932-938.

32. National Toxicology Program. NTP-CERHR MON monograph on the potential Human reproductive and developmental effects of hydroxyurea. 2008 Oct;(21)i-III1 http://cerhr niehs nih gov

33. Berthaut I, Guignedoux G, Kirsch-Noir F, de Larouziere V, Ravel C, Bachir D, et al. Influence of sickle cell disease and treatment with hydroxyurea on sperm parameters and fertility of human males. Haematologica. 2008;93(7):988-992.

34. Garozzo G. Azoospermia in a patient with sickle cell disease treated with hydroxyurea. Haematologica. 2000;85:1216-1218.

35. Grigg A. Effect of hydroxyurea on sperm count, motility and morphology in adult men with sickle cell or myeloproliferative disease. Int Med J. 2007;37:190-192.

36. Bader U, Banyai M, Boni R, Burg G, Hafner J. Leg ulcers in patients with myeloproliferative disorders:disease or treatment related. Dermatology. 2000;200:45-48.

37. Standards for the Clincial Care of Adults with Sickle Cell Disease in the UK. Published by Sickle Cell Society. 2008. www. sicklecellsociety.org

38. Antenatal and Newborn Screening Programs: Sickle cell disease in childhood: Standards and guidelines for clinical care 2006. NHS Sickle Cell and Thalassaemia Screening Program.

39. Adams RJ. TCD in sickle cell disease: an important and useful test. Ped Radiol. 2005;35:229-234.

40. Switzer JA, Hess DC, Nichols FT, Adams RJ. Pathophysiology and treatment of stroke in sickle cell disease: present and future. Lancet Neurol. 2006;5:501-512.

41. Zimmerman SA, Schultz WH, Burgett S, Mortier NA, Ware RE. Hydroxyurea therapy lowers transcranial Doppler flow velocities in children with sickle cell anaemia. Blood. 2007;110:1043-1047.

42. Thornburg CD, Dixon N, Burgett S, et al. A pilot study of hydroxyurea to prevent chronic organ damage in young children with Sickle Cell Anaemia. Pediatr Blood Cancer. 2009;52:609-615

43. Ware RE, Zimmerman SA, Schultz WH. Hydroxyurea as an alternative to blood transfusions for the prevention of recurrent stroke in children with sickle cell disease. Blood. 1999;9:3022-3026.

44. Sumoza A, Biscotti R, Sumoza D, Fairbanks V. Hydroxyurea for prevention of recurrent stroke in sickle cell anaemia. Am J Hematol. 2002;71:161-165.

45. National Heart, Lung, and Blood Institute (NHLBI). Stroke With Transfusions Changing to Hydroxyurea (SWiTCH). Clinical Trials. Gov. NCT00122980.

46. Hankins JS, Helton KJ, McCarville MB, Li CS, Wang WC, Ware RF. Preservation of spleen and brain function in children with sickle cell anaemia treated with hydroxyurea. Pediatr Blood Cancer. 2008;50: 293-297.

47. Fitzhugh CD, Wigfall DR, Ware RE. Enalapril and hydroxyurea therapy for children with sickle nephropathy. Pediatr Blood Cancer. 2005; 45:982-985

48. Miller MK, Zimmerman SA, Schultz WH, Ware RE. Hydroxyurea therapy for pediatric patients with hemoglobin SC disease. $J$ Pediatr Hematol Oncol. 2001;23:306-308. 
49. Singh SA, Koumbourlis AC, Aygun B. Resolution of chronic hypoxia in pediatric sickle cell patients after treatment with hydroxyurea Pediatr Blood Cancer. 2008;50:1258-1260.

50. Raghupathy R, Billett HH. Promising therapies in sickle cell disease. Cardiovasc Hematol Disord Drug Targets. 2009;9(1):1-8.
51. Little JA, McGowan VR, Kato GJ, et al. Combination erthropoetinhydroxyurea therapy in sickle cell disease: experience from the National Institutes of Health and a literature review. Haematologica. 2006;91(8):1076-1083.

\section{Publish your work in this journal}

Therapeutics and Clinical Risk Management is an international, peerreviewed journal of clinical therapeutics and risk management, focusing on concise rapid reporting of clinical studies in all therapeutic areas, outcomes, safety, and programs for the effective, safe, and sustained use of medicines. This journal is indexed on PubMed Central, CAS,
EMBase, Scopus and the Elsevier Bibliographic databases. The manuscript management system is completely online and includes a very quick and fair peer-review system, which is all easy to use. Visit http://www.dovepress.com/testimonials.php to read real quotes from published authors.

Submit your manuscript here: http://www.dovepress.com/therapeutics-and-clinical-risk-management-journal 